\title{
Associations of mutually exclusive categories of physical activity and sedentary time with markers of cardiometabolic health in English adults: a cross-sectional analysis of the Health Survey for England
}

Kishan Bakrania ${ }^{1,2,3}$, Charlotte L. Edwardson ${ }^{2,3^{*}}$, Danielle H. Bodicoat ${ }^{2}$, Dale W. Esliger ${ }^{3,4}$, Jason M. R. Gill ${ }^{5}$, Aadil Kazi ${ }^{2,3}$, Latha Velayudhan ${ }^{6}$, Alan J. Sinclair ${ }^{7}$, Naveed Sattar ${ }^{5}$, Stuart J. H. Biddle ${ }^{8}$, Kamlesh Khuntii ${ }^{2,9}$, Melanie Davies ${ }^{2,3}$ and Thomas Yates 2,3

\begin{abstract}
Background: Both physical activity and sedentary behaviour have been individually associated with health, however, the extent to which the combination of these behaviours influence health is less well-known. The aim of this study was to examine the associations of four mutually exclusive categories of objectively measured physical activity and sedentary time on markers of cardiometabolic health in a nationally representative sample of English adults.

Methods: Using the 2008 Health Survey for England dataset, 2131 participants aged $\geq 18$ years, who provided valid accelerometry data, were included for analysis and grouped into one of four behavioural categories: (1) 'Busy Bees': physically active \& low sedentary, (2) 'Sedentary Exercisers': physically active \& high sedentary, (3) 'Light Movers': physically inactive \& low sedentary, and (4) 'Couch Potatoes': physically inactive \& high sedentary. 'Physically active' was defined as accumulating at least 150 min of moderate-to-vigorous physical activity (MVPA) per week. 'Low sedentary' was defined as residing in the lowest quartile of the ratio between the average sedentary time and the average light-intensity physical activity time. Weighted multiple linear regression models, adjusting for measured confounders, investigated the differences in markers of health across the derived behavioural categories. The associations between continuous measures of physical activity and sedentary levels with markers of health were also explored, as well as a number of sensitivity analyses.

(Continued on next page)
\end{abstract}

\footnotetext{
* Correspondence: ce95@le.ac.uk

²Diabetes Research Centre, University of Leicester, Leicester Diabetes Centre, Leicester General Hospital, Gwendolen Road, Leicester LE5 4PW, UK ${ }^{3}$ National Institute for Health Research (NIHR) Leicester-Loughborough Diet, Lifestyle and Physical Activity Biomedical Research Unit (BRU), Leicester Diabetes Centre, Leicester General Hospital, Gwendolen Road, Leicester LE5 4PW, UK

Full list of author information is available at the end of the article
} 


\begin{abstract}
(Continued from previous page)
Results: In comparison to 'Couch Potatoes', 'Busy Bees' [body mass index: $-1.67 \mathrm{~kg} / \mathrm{m}^{2}(p<0.001)$; waist circumference: $-1.17 \mathrm{~cm}(p=0.007)$; glycated haemoglobin: $-0.12 \%(p=0.003)$; HDL-cholesterol: $0.09 \mathrm{mmol} / \mathrm{L}$ $(p=0.001)$ ], 'Sedentary Exercisers' [body mass index: $-1.64 \mathrm{~kg} / \mathrm{m}^{2}(p<0.001)$; glycated haemoglobin: $-0.11 \%$ $(p=0.009)$; HDL-cholesterol: $0.07 \mathrm{mmol} / \mathrm{L}(p<0.001)]$ and 'Light Movers' [HDL-cholesterol: $0.11 \mathrm{mmol} / \mathrm{L}(p=0.004)]$ had more favourable health markers. The continuous analyses showed consistency with the categorical analyses and the sensitivity analyses indicated robustness and stability.

Conclusions: In this national sample of English adults, being physically active was associated with a better health profile, even in those with concomitant high sedentary time. Low sedentary time independent of physical activity had a positive association with HDL-cholesterol.
\end{abstract}

Keywords: Accelerometry, Objective, Physical activity, Sedentary, Cardiometabolic health

\section{Background}

There is increasing evidence that sedentary behaviour, characterised as any waking behaviour with low energy expenditure ( $\leq 1.5$ metabolic equivalents) while in a sitting or reclining posture [1], is strongly associated with a number of health outcomes [2-8]. These studies have shown that high levels of sedentary behaviour are associated with a greater risk of morbidity and mortality, which is potentially concerning given that most adults spend the majority of their waking hours $(\sim 55 \%$ to $\sim 70$ $\%)$ engaging in this behaviour [9-12]. In contrast, it is known that high levels of physical activity, particularly moderate-to-vigorous physical activity (MVPA), are associated with improved health, often in a dose-response manner [13-15]. Sedentary behaviour and MVPA share a weak inverse relationship and it is possible for an individual, over the course of a day, to have high levels of physical activity and still accumulate large amounts of sedentary time [16-18].

Previous research has largely focused on the independent associations of total physical activity, MVPA, lightintensity physical activity and sedentary time on health $[2-8,16-27]$, rather than the interplay between these constructs. As a consequence, the daily equilibrium between physical activity and sedentary behaviour, and the pooled relationship they share with biomarkers of health, is not fully understood. Although some studies have started to explore different techniques for quantifying combined connections and patterns of MVPA and sedentary behaviour [28-35], to our knowledge, only one study based in the USA has investigated the associations between categories of physical activity and sedentary time with markers of health [36]. Loprinzi and colleagues found that in comparison to adults who engaged in $<150 \mathrm{~min} /$ week of MVPA with high sedentary time (sedentary time $>$ light-intensity physical activity time), participants engaging in $\geq 150 \mathrm{~min} /$ week of MVPA had a more favourable cardiometabolic health profile regardless of their sedentary status [36], suggesting that regular MVPA may offset some of the harmful consequences of a habitually sedentary lifestyle. If verified, this would be a clinically important message for a large proportion of the population who may be concerned about the amount of time they spend sitting.

The aim of this paper is to use the 2008 Health Survey for England (HSE) [11, 37] dataset to examine and quantify the combined categories of objectively measured physical activity and sedentary time amongst English adults and associate these factors to clinically relevant anthropometric and biochemical markers of cardiometabolic health.

\section{Methods \\ Study sample}

The HSE is a series of national annual surveys designed to examine the health and well-being of people living in England [11, 37]. In order to obtain a population-based sample, these cross-sectional surveys employ a multistage stratified random sampling procedure with postcode regions acting as the primary sampling unit. The 2008 wave was centred on physical activity and fitness and sampled 22623 participants [aged $\geq 2$ years]. Six thousand two hundred and fourteen individuals [aged $\geq 4$ years] were randomly selected and approached to wear an accelerometer. Adults [aged $\geq 18$ years] who had accelerometry data available were included in the present study $(n=2313)$. Participants provided written informed consent. Ethical approval for the 2008 HSE survey was obtained from the Oxford A Research Ethics Committee (reference number 07/H0604/102). Further details regarding this sample can be found elsewhere $[11,37]$.

\section{Measuring physical activity and sedentary time}

Physical activity and sedentary time were measured using an ActiGraph GT1M accelerometer (ActiGraph Corporation, Pensacola, Florida, USA) worn on the right hip for seven consecutive days during waking hours (except water-based activities) [11]. The ActiGraph GT1M device was initialised to collect data using one minute epochs. Accelerometer files were processed using KineSoft 
V3.3.76 (KineSoft, Loughborough, UK). Accelerometer counts were used to calculate the time spent in each intensity band: sedentary behaviour $(<100$ counts per min (cpm)), light-intensity physical activity (100-1951 cpm) and MVPA ( $\geq 1952 \mathrm{cpm}$ ) [38]. In addition, MVPA time accumulated in bouts of $\geq 10 \mathrm{~min}$, allowing for a two minute exception in the intensity threshold, was also derived. Non-wear time was defined as any periods of continuous zero counts for $\geq 60$ consecutive min [39]. A valid day was defined as $\geq 10$ hours (i.e. $\geq 600 \mathrm{~min}$ ) of weartime. Adults who provided $\geq 4$ days of valid accelerometer data were included.

\section{Derivation of the behavioural categories}

For each individual, the average number of minutes per valid day spent in MVPA, light-intensity physical activity and sedentary behaviour were calculated. Based upon other studies $[36,40]$, the sedentary behaviour-to-light-intensity physical activity ratio (average sedentary time : average light-intensity physical activity time) was used for the classification of sedentary status. Participants were then split into quartiles based on this ratio. Given that the levels of sedentary behaviour in the general population are predominantly high [9-12], a conservative, data-driven approach was undertaken and individuals were classified as 'low sedentary' if they resided in quartile 1 and 'high sedentary' if they resided in quartiles 2, 3 or 4. MVPA status was classified as 'physically active' or 'physically inactive' on the basis of whether or not participants accumulated at least $150 \mathrm{~min}$ of MVPA per week. This allowed the formation of four mutually exclusive behavioural categories (Fig. 1), which are provided with communicative names to aid interpretability: (1) 'Busy Bees': physically active \& low sedentary, (2) 'Sedentary Exercisers': physically active \& high sedentary, (3) 'Light Movers': physically inactive \& low sedentary, and (4) 'Couch Potatoes': physically inactive \& high sedentary.

\section{Markers of cardiometabolic health}

A trained interviewer recorded height (measured to the nearest $0.1 \mathrm{~cm}$ using a portable stadiometer) and weight (measured to the nearest $0.1 \mathrm{~kg}$ using an electronic scale) readings [37]. Body Mass Index (BMI) was calculated as the weight (in kilograms) divided by the square of the height (in metres). Waist circumference was defined as the midpoint between the lower rib and the upper boundary of the iliac crest. A nurse measured this twice to the nearest $0.1 \mathrm{~cm}$ using a tape and the mean of the two readings was used [37]. Non-fasting blood samples were collected by the nurse for the analysis of high-

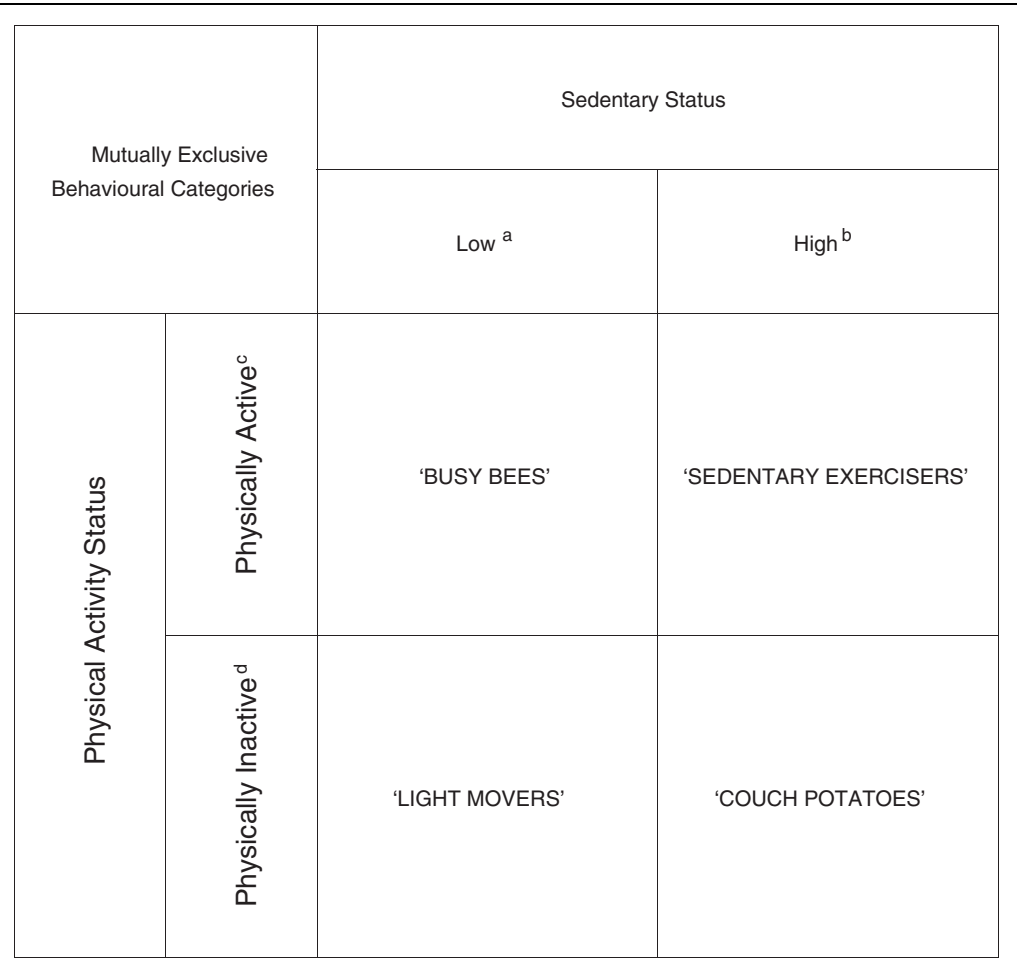

Fig. 1 Mutually exclusive behavioural categories. 'Busy Bees': Physically Active and Low Sedentary, 'Sedentary Exercisers': Physically Active and High Sedentary, 'Light Movers': Physically Inactive and Low Sedentary, 'Couch Potatoes': Physically Inactive and High Sedentary. ${ }^{a}$ Low Sedentary: Quartile 1 of the ratio between the average sedentary time and the average light-intensity physical activity time. ${ }^{\mathrm{b}}$ High Sedentary: Quartiles 2, 3 or 4 of the ratio between the average sedentary time and the average light-intensity physical activity time. ${ }^{c}$ Physically Active: $\geq 150$ min of moderate-to-vigorous physical activity per week. ${ }^{\mathrm{d}}$ Physically Inactive: $<150$ min of moderate-to-vigorous physical activity per week 
density lipoprotein (HDL) cholesterol, total cholesterol and glycated haemoglobin (HbA1c). Blood analytes were assayed at the Royal Victoria Infirmary laboratory in Newcastle upon Tyne, England. Further details regarding these variables can be found elsewhere [37].

\section{Contextual variables}

The following factors, collected by a trained interviewer [37], were also utilised: age (in years); cardiovascular disease index (no cardiovascular diseases, one or more cardiovascular diseases); fruit and vegetable consumption ( $0,1-3,4-6,7+$ portions per day); ethnicity (white, non-white); sex (male, female); smoking status (never smoked, ex-smoker, current smoker); socioeconomic status (national statistics socioeconomic classification: high, high-intermediate, intermediate, lowintermediate, low); blood pressure medication (no, yes); cholesterol medication (no, yes); and any other prescribed medication (no, yes). The 'cardiovascular disease index' variable was based on the following physician diagnosed cardiovascular conditions/events: abnormal heart rhythm; angina; atrial fibrillation; congenital heart disease; heart attack; heart transplant; heart valve disease; intermittent claudication; stroke; and transient ischaemic attack.

\section{Statistical analysis}

All statistical analyses were conducted using Stata/IC V13.1 (Stata Corporation, College Station, Texas, USA) and controlled for the complex survey strategy employed in the 2008 HSE (primary sampling units, clustering and survey weights) $[11,37]$. Interview weights, which adjusted for: household selection; non-response bias; age; sex; and regional profiles, were applied in order to produce estimates representing the national population. Nurse weights (generated from interview weights) were utilised to further reduce non-response bias arising from individuals who were interviewed but did not have a nurse visit. Blood weights (generated from nurse weights) were utilised to analyse the blood related variables.

\section{Categorical associations}

Pairwise deletion was used throughout the study for handling any missing data. The weighted prevalence [n; $\%$ ] of the English adults in each mutually exclusive behavioural category were computed. Participant characteristics of the full sample, stratified by each category, were tabulated. Categorical variables were presented as proportions [n; \%], whereas the continuous variables were summarised via their means and standard errors. Univariate linear regression models, with 'behavioural category' as the independent variable, were fitted for the following assessed health markers: BMI; waist circumference; HDL-cholesterol; total cholesterol; and HbA1c. The 'Couch Potatoes' category, representing physically inactive adults with high sedentary time (i.e. the least desirable group), was selected as the reference category. Subsequently, multiple linear regression models were also fitted for each dependent variable with the following covariates: age; BMI (except in the model with BMI as the dependent variable); cardiovascular disease index; ethnicity; fruit and vegetable consumption; sex; smoking status; socioeconomic status; and accelerometer weartime. Models with HDL-cholesterol and total cholesterol as the dependent variable were also controlled for both blood pressure medication and cholesterol medication. Similarly, the model with $\mathrm{HbA1c}$ as the dependent variable was controlled for any prescribed medication. All regression analyses were two-sided where $p<0.01$ was considered to be statistically significant to account for multiple comparisons.

The following sensitivity analyses, examining the robustness of the main effects, were also investigated: (1) missing data in the covariates were imputed using the behavioural category means (continuous variables: BMI) and modes (categorical variables: smoking status and socioeconomic status), (2) participants with a cardiovascular disease index of 'one or more cardiovascular diseases' were excluded, (3) 'Low Sedentary' was defined as residing in the lowest tertile of the ratio between the average sedentary time and the average light-intensity physical activity time, and (4) participants were only classified into the 'physically active' categories if they accumulated $\geq 150$ min of MVPA per week in bouts of $\geq 10 \mathrm{~min}$. For each sensitivity analysis, the weighted behavioural category prevalence and health associations were reported.

\section{Continuous associations}

The associations between continuous measures of physical activity and sedentary levels with markers of health were also investigated. Multiple linear regression models were fitted for each health marker whilst controlling for the appropriate corresponding confounders as well as both continuous MVPA time and sedentary status (sedentarybehaviour-to-light-intensity physical activity ratio). Analogous to the categorical analyses, these regression analyses were also two-sided with $p<0.01$ considered to be statistically significant.

\section{Results}

A total of 2131 adults were available for analysis after retaining only those individuals who provided $\geq 4$ valid days of accelerometer data. The four groups were comprised as follows: (1) 'Busy Bees': $n=385 ; 18.6 \%$, (2) 'Sedentary Exercisers': $n=743 ; 36.7 \%$, (3) 'Light Movers': $n=147 ; 6.8 \%$, and (4) 'Couch Potatoes': $n=856 ; 37.9 \%$. Table 1 presents the characteristics of the participants. 
Table 1 Participant characteristics

\begin{tabular}{|c|c|c|c|c|c|}
\hline Characteristic & $\begin{array}{l}\text { Sample } \\
N=2131\end{array}$ & $\begin{array}{l}\text { 'Busy Bees' } \\
n=385 ; 18.6 \%\end{array}$ & $\begin{array}{l}\text { 'Sedentary Exercisers' } \\
n=743 ; 36.7 \%\end{array}$ & $\begin{array}{l}\text { 'Light Movers' } \\
n=147 ; 6.8 \%\end{array}$ & $\begin{array}{l}\text { 'Couch Potatoes' } \\
n=856 ; 37.9 \% \\
\end{array}$ \\
\hline Age (in years) ${ }^{a}$ & $50.8(0.47)$ & $44.8(0.72)$ & $45.6(0.72)$ & $49.8(1.27)$ & $58.9(0.74)$ \\
\hline \multicolumn{6}{|l|}{ Cardiovascular Disease Index ${ }^{\mathrm{b}}$} \\
\hline No Cardiovascular Diseases & 2030 (95.6) & $374(97.4)$ & $707(95.7)$ & $141(96.2)$ & $808(94.6)$ \\
\hline One or More Cardiovascular Diseases & $101(4.4)$ & $11(2.6)$ & $36(4.3)$ & $6(3.8)$ & $48(5.4)$ \\
\hline \multicolumn{6}{|l|}{ Ethnicity ${ }^{b}$} \\
\hline White & 2008 (93.2) & $364(93.6)$ & $691(92.1)$ & $141(95.1)$ & $812(93.8)$ \\
\hline Non-White & $123(6.8)$ & $21(6.4)$ & $52(7.9)$ & $6(4.9)$ & $44(6.2)$ \\
\hline \multicolumn{6}{|l|}{ Fruit \& Vegetable Consumption (portions per day) ${ }^{b}$} \\
\hline 0 & $95(4.5)$ & $25(6.1)$ & $29(3.9)$ & $8(5.5)$ & $33(4.0)$ \\
\hline $1-3$ & $680(32.4)$ & $128(34.8)$ & $221(30.6)$ & $46(30.9)$ & $285(33.4)$ \\
\hline $4-6$ & $968(45.3)$ & $152(39.0)$ & $359(48.0)$ & $69(48.4)$ & $388(45.3)$ \\
\hline $7+$ & $388(17.8)$ & $80(20.1)$ & $134(17.5)$ & $24(15.2)$ & $150(17.3)$ \\
\hline \multicolumn{6}{|l|}{ Sex ${ }^{b}$} \\
\hline Male & $981(49.3)$ & $172(48.8)$ & $414(59.0)$ & $36(28.8)$ & $359(43.8)$ \\
\hline Female & $1150(50.7)$ & $213(51.2)$ & $329(41.0)$ & $111(71.2)$ & $497(56.2)$ \\
\hline \multicolumn{6}{|l|}{ Smoking Status ${ }^{\mathrm{b}}$} \\
\hline Never Smoked & $993(47.1)$ & $171(44.5)$ & $393(53.7)$ & $57(37.8)$ & $372(43.6)$ \\
\hline Ex-Smoker & $726(32.7)$ & $113(28.6)$ & $232(29.5)$ & $51(34.0)$ & $330(37.5)$ \\
\hline Current Smoker & $410(20.1)$ & $101(26.9)$ & $116(16.4)$ & $39(28.2)$ & $154(18.9)$ \\
\hline Missing $^{c}$ & $2(0.1)$ & $0(0.0)$ & $2(0.4)$ & $0(0.0)$ & $0(0.0)$ \\
\hline \multicolumn{6}{|l|}{ Socioeconomic Status ${ }^{\mathrm{b}}$} \\
\hline High & $769(36.7)$ & $80(20.5)$ & $358(49.0)$ & $34(22.5)$ & $297(35.1)$ \\
\hline High-Intermediate & $276(12.4)$ & $41(9.6)$ & $100(13.2)$ & $22(13.4)$ & $113(12.8)$ \\
\hline Intermediate & $203(9.5)$ & $48(12.4)$ & $48(6.2)$ & $18(13.7)$ & $89(10.5)$ \\
\hline Low-Intermediate & $191(9.3)$ & $52(15.0)$ & $44(5.8)$ & $14(11.4)$ & $81(9.6)$ \\
\hline Low & $646(29.8)$ & $154(40.1)$ & $177(23.3)$ & $58(38.5)$ & $257(29.5)$ \\
\hline Missing $^{c}$ & $46(2.3)$ & $10(2.4)$ & $16(2.5)$ & $1(0.5)$ & $19(2.5)$ \\
\hline \multicolumn{6}{|l|}{ Blood Pressure Medication ${ }^{\text {b }}$} \\
\hline No & $1629(78.7)$ & $349(91.1)$ & $636(87.6)$ & $119(82.5)$ & $525(63.4)$ \\
\hline Yes & $502(21.3)$ & $36(8.9)$ & $107(12.4)$ & $28(17.5)$ & $331(36.6)$ \\
\hline \multicolumn{6}{|l|}{ Cholesterol Medication ${ }^{\mathrm{b}}$} \\
\hline No & $1797(85.8)$ & $366(95.7)$ & $669(91.3)$ & $129(88.5)$ & $633(75.2)$ \\
\hline Yes & $334(14.2)$ & $19(4.3)$ & $74(8.7)$ & $18(11.5)$ & $223(24.8)$ \\
\hline \multicolumn{6}{|l|}{ Any Prescribed Medication ${ }^{b}$} \\
\hline No & $1031(51.2)$ & $238(63.2)$ & $426(60.1)$ & $80(57.4)$ & $287(35.5)$ \\
\hline Yes & $1100(48.8)$ & $147(36.8)$ & $317(39.9)$ & $67(42.6)$ & $569(64.5)$ \\
\hline $\begin{array}{l}\text { Moderate-to-Vigorous Physical Activity Time } \\
\text { (no. of minutes per valid day) }\end{array}$ & $30.3(0.59)$ & $51.3(1.46)$ & $44.0(0.80)$ & $13.2(0.39)$ & $9.7(0.22)$ \\
\hline Sedentary Time ${ }^{a}$ (no. of minutes per valid day) & $540.2(2.29)$ & $417.2(3.62)$ & $564.5(2.68)$ & $435.5(3.84)$ & $595.7(2.39)$ \\
\hline $\begin{array}{l}\text { Light-Intensity Physical Activity Time }{ }^{a} \\
\text { (no. of minutes per valid day) }\end{array}$ & $289.1(2.06)$ & $394.9(3.16)$ & $260.5(1.88)$ & $396.2(4.35)$ & $245.9(2.47)$ \\
\hline Accelerometer Wear-Time ${ }^{a}$ (no. of minutes per valid day) & $859.7(1.72)$ & $863.5(4.53)$ & $869.1(2.69)$ & $844.9(5.65)$ & $851.4(2.78)$ \\
\hline Sedentary-to-Light-Intensity Physical Activity Time Ratio ${ }^{a}$ & $2.2(0.03)$ & $1.1(0.01)$ & $2.3(0.03)$ & $1.1(0.01)$ & $2.8(0.05)$ \\
\hline
\end{tabular}


Table 1 Participant characteristics (Continued)

\begin{tabular}{|c|c|c|c|c|c|}
\hline \multicolumn{6}{|l|}{ Number of Valid Days ${ }^{b}$} \\
\hline 4 & $99(4.9)$ & $18(4.7)$ & $35(5.1)$ & $8(5.7)$ & $38(4.8)$ \\
\hline 5 & $185(9.1)$ & $36(9.7)$ & $55(8.1)$ & $21(14.6)$ & $73(8.8)$ \\
\hline 6 & $414(20.4)$ & $80(21.0)$ & $139(20.1)$ & $32(23.5)$ & $163(20.0)$ \\
\hline 7 & $1433(65.6)$ & $251(64.6)$ & $514(66.7)$ & $86(56.2)$ & $582(66.4)$ \\
\hline Body Mass Index $\left(\mathrm{kg} / \mathrm{m}^{2}\right)^{\mathrm{a}}$ & $27.5(0.12)$ & $26.6(0.24)$ & $26.8(0.17)$ & $27.6(0.43)$ & $28.7(0.21)$ \\
\hline Missing ${ }^{c}$ & $185(8.7)$ & $30(7.8)$ & $44(5.9)$ & $8(5.4)$ & $103(12.0)$ \\
\hline Waist Circumference $(\mathrm{cm})^{\mathrm{a}}$ & $93.4(0.36)$ & $90.1(0.70)$ & $91.7(0.57)$ & $91.5(1.18)$ & $97.0(0.55)$ \\
\hline Missing ${ }^{c}$ & $242(11.4)$ & $44(11.4)$ & $80(10.8)$ & $17(11.6)$ & $101(11.8)$ \\
\hline HDL-Cholesterol $(\mathrm{mmol} / \mathrm{L})^{\mathrm{a}}$ & $1.49(0.01)$ & $1.53(0.02)$ & $1.49(0.02)$ & $1.58(0.04)$ & $1.44(0.01)$ \\
\hline Missing ${ }^{c}$ & $728(34.2)$ & $120(31.2)$ & $245(33.0)$ & $51(34.7)$ & $312(36.4)$ \\
\hline Total Cholesterol $(\mathrm{mmol} / \mathrm{L})^{\mathrm{a}}$ & $5.42(0.03)$ & $5.37(0.06)$ & $5.49(0.05)$ & $5.48(0.12)$ & $5.37(0.05)$ \\
\hline Missing ${ }^{c}$ & $728(34.2)$ & $120(31.2)$ & $245(33.0)$ & $51(34.7)$ & $312(36.4)$ \\
\hline Glycated Haemoglobin (\%) ${ }^{a}$ & $5.64(0.02)$ & $5.47(0.02)$ & $5.51(0.02)$ & $5.89(0.14)$ & $5.82(0.04)$ \\
\hline Missing $^{c}$ & $746(35.0)$ & $127(33.0)$ & $250(33.6)$ & $52(35.4)$ & $317(37.0)$ \\
\hline
\end{tabular}

All analyses accounted for primary sampling units, clustering and survey weights

'Busy Bees': Physically Active and Low Sedentary, 'Sedentary Exercisers': Physically Active and High Sedentary, 'Light Movers': Physically Inactive and Low Sedentary, 'Couch Potatoes': Physically Inactive and High Sedentary

${ }^{a}$ Continuous variable; Mean (Standard Error)

${ }^{\mathrm{b}}$ Categorical variable; $n$ (Proportion (\%))

${ }^{c}$ Missing data; $\mathrm{n}(\%)$

\section{Categorical associations}

The unadjusted and adjusted categorical analyses are displayed in Table 2 and Additional file 1: Figure S1. The adjusted analyses showed that in comparison to 'Couch Potatoes', 'Busy Bees' had significantly lower BMI $(p<0.001)$, waist circumference $(p=0.007)$ and HbA1c $(p=0.003)$ levels, and higher HDL-cholesterol $(p=0.001)$ levels. Similarly, 'Sedentary Exercisers' had significantly lower BMI $(p<0.001)$ and $\operatorname{HbA1c}(p=0.009)$ levels, and higher HDL-cholesterol $(p<0.001)$ levels. 'Light Movers' had significantly higher HDL-cholesterol $(p=0.004)$ levels.

The sensitivity analyses, including an alternative less conservative method for classifying sedentary status, indicated robustness and stability. Although the prevalence in each category varied across the different methods

Table 2 Categorical associations with markers of cardiometabolic health (beta coefficients (99\% Cls) and corresponding p-values)

\begin{tabular}{|c|c|c|c|c|c|c|c|c|}
\hline \multirow[t]{2}{*}{ Health marker } & \multirow{2}{*}{$\begin{array}{l}\text { Linear } \\
\text { regression } \\
\text { model }\end{array}$} & \multicolumn{2}{|l|}{ 'Busy Bees' } & \multicolumn{2}{|l|}{ 'Sedentary Exercisers' } & \multicolumn{2}{|l|}{ 'Light Movers' } & \multirow{2}{*}{$\begin{array}{l}\text { 'Couch } \\
\text { Potatoes' }\end{array}$} \\
\hline & & Beta $(99 \% \mathrm{Cl})$ & $p$-value & Beta $(99 \% \mathrm{Cl})$ & $p$-value & Beta $(99 \% \mathrm{Cl})$ & $p$-value & \\
\hline \multirow[t]{2}{*}{ Body Mass Index $\left(\mathrm{kg} / \mathrm{m}^{2}\right)$} & Unadjusted & $-2.06(-2.86,-1.26)$ & $<0.001$ & $-1.93(-2.61,-1.25)$ & $<0.001$ & $-1.04(-2.26,0.18)$ & 0.027 & $\overline{\text { Reference }}$ \\
\hline & Adjusted & $-1.67(-2.57,-0.77)$ & $<0.001$ & $-1.64(-2.43,-0.85)$ & $<0.001$ & $-0.66(-1.92,0.60)$ & 0.175 & Reference \\
\hline \multirow[t]{2}{*}{ Waist Circumference (cm) } & Unadjusted & $-6.92(-9.17,-4.68)$ & $<0.001$ & $-5.31(-7.33,-3.30)$ & $<0.001$ & $-5.53(-8.89,-2.16)$ & $<0.001$ & Reference \\
\hline & Adjusted & $-1.17(-2.28,-0.06)$ & 0.007 & $-0.71(-1.56,0.14)$ & 0.032 & $-0.07(-1.61,1.47)$ & 0.908 & Reference \\
\hline \multirow[t]{2}{*}{ HDL-Cholesterol (mmol/L) } & Unadjusted & $0.09(0.02,0.17)$ & 0.001 & $0.05(-0.01,0.11)$ & 0.021 & $0.14(0.04,0.24)$ & $<0.001$ & Reference \\
\hline & Adjusted & $0.09(0.02,0.16)$ & 0.001 & $0.07(0.02,0.13)$ & $<0.001$ & $0.11(0.01,0.21)$ & 0.004 & Reference \\
\hline \multirow[t]{2}{*}{ Total Cholesterol (mmol/L) } & Unadjusted & $-0.00(-0.21,0.21)$ & 0.981 & $0.12(-0.06,0.29)$ & 0.081 & $0.11(-0.23,0.45)$ & 0.408 & Reference \\
\hline & Adjusted & $0.02(-0.17,0.22)$ & 0.761 & $0.17(-0.01,0.35)$ & 0.014 & $0.08(-0.22,0.38)$ & 0.490 & Reference \\
\hline \multirow[t]{2}{*}{ Glycated Haemoglobin (\%) } & Unadjusted & $-0.35(-0.47,-0.24)$ & $<0.001$ & $-0.32(-0.43,-0.20)$ & $<0.001$ & $0.07(-0.32,0.46)$ & 0.656 & Reference \\
\hline & Adjusted & $-0.12(-0.22,-0.01)$ & 0.003 & $-0.11(-0.23,-0.01)$ & 0.009 & $0.26(-0.11,0.63)$ & 0.072 & Reference \\
\hline
\end{tabular}

All analyses accounted for primary sampling units, clustering and survey weights. Unadjusted and adjusted linear regression models were fitted for each cardiometabolic health marker with the 'Couch Potatoes' category selected as the reference group. The adjusted linear regression models controlled for: age; body mass index (except in the model with body mass index as the dependent variable); cardiovascular disease index; ethnicity; fruit and vegetable consumption; sex; smoking status; socioeconomic status; and accelerometer wear-time. Models with HDL-cholesterol and total cholesterol as the dependent variable were also controlled for both blood pressure medication and cholesterol medication. Similarly, the model with glycated haemoglobin as the dependent variable was controlled for any prescribed medication. Bold indicates statistical significance at $a=0.01$

'Busy Bees': Physically Active and Low Sedentary, 'Sedentary Exercisers': Physically Active and High Sedentary, 'Light Movers': Physically Inactive and Low Sedentary, 'Couch Potatoes': Physically Inactive and High Sedentary 
used (Additional file 1: Table S1), the main results from the primary multiple linear regression models were largely unaffected (Additional file 1: Table S2).

\section{Continuous associations}

The adjusted continuous analyses are displayed in Table 3 and showed consistency with the categorical analyses. These models, which controlled for relevant confounders as well as both MVPA time and sedentary status, revealed that MVPA time was significantly associated with lower BMI $(p<0.001)$, waist circumference $(p<0.001)$ and HbA1c $(p=0.002)$ levels, and higher HDL-cholesterol $(p<0.001)$ levels. In contrast, sedentary status was significantly associated with lower HDL-cholesterol $(p=0.004)$ levels.

\section{Discussion}

This is the first study to quantify associations of mutually exclusive categories of objectively measured physical activity and sedentary time with markers of cardiometabolic health in a nationally representative sample of English adults. Overall, adults who engaged in at least $150 \mathrm{~min}$ of MVPA per week, including those with concomitant high sedentary time ('Sedentary Exercisers'), had more favourable health profiles compared to physically inactive individuals with high sedentary time ('Couch Potatoes'). Low sedentary time independent of physical activity ('Light Movers') had positive associations with HDLcholesterol. These findings were consistent with the sensitivity and continuous analyses.

The approach to categorising the population into one of four mutually exclusive categories extends previous research using HSE. For example, previous analysis of HSE has reported associations between both self-reported and objectively assessed sedentary time with markers of health in working age and older adults and between MVPA and markers of health [25-27]. The wider evidence has increasingly demonstrated that objectively measured sedentary time is independently associated with markers of cardiometabolic health [16-20, 41, 42], although not all studies have demonstrated this link [43]. Whilst these previous analyses have adjusted for MVPA, the associations of sedentary time with health across physical activity levels are less well understood. Therefore, this study adds to the evidence by investigating associations of sedentary status with health across categories of physical activity.

Our findings are in broad agreement with the only other study to have used a similar methodology [36]. Using national survey data from the USA, Loprinzi and colleagues found that in comparison to individuals (aged $\geq 20$ years) who engaged in $<150 \mathrm{~min} /$ week of MVPA with high sedentary time (sedentary time $>$ light-intensity physical activity time), individuals engaging in $\geq 150 \mathrm{~min} /$ week of MVPA had a more favourable cardiometabolic profile (BMI, waist circumference, C-reactive protein, white blood cells and neutrophils) regardless of their sedentary status. [36] Participants in the most desirable group ( $\geq 150 \mathrm{~min} /$ week of MVPA with low sedentary time) also had better HDL-cholesterol, triglyceride and insulin levels. Similar to our study, participants in the physically inactive group with low sedentary time had fewer beneficial associations, although more favourable profiles for triglycerides and insulin levels were still observed.

Our findings, alongside those of Loprinzi and colleagues [36], are also consistent with the emerging evidence that levels of fitness or physical activity may modify the associations between sedentary time and markers of health in adults [35, 41, 44, 45], with sedentary behaviour only emerging as a determinant of health in those who are inactive or unfit. Together, these studies suggest that being physically active may confer some protection from the potentially deleterious impact of high sedentary behaviour.

In our study, low sedentary time in the absence of being physically active ('Light Movers') was associated with

Table 3 Continuous associations with markers of cardiometabolic health (beta coefficients (99\% Cls) and corresponding p-values)

\begin{tabular}{|c|c|c|c|c|}
\hline \multirow[t]{2}{*}{ Health marker } & \multicolumn{2}{|c|}{ Moderate-to-vigorous physical activity time } & \multicolumn{2}{|c|}{ Sedentary behaviour-to-light-intensity physical activity ratio } \\
\hline & Beta $(99 \% \mathrm{Cl})^{a}$ & $p$-value & Beta $(99 \% \mathrm{Cl})^{\mathrm{b}}$ & $p$-value \\
\hline Body Mass Index $\left(\mathrm{kg} / \mathrm{m}^{2}\right)$ & $-0.0393(-0.0505,-0.0282)$ & $<0.001$ & $-0.1109(-0.3918,0.1700)$ & 0.305 \\
\hline Waist Circumference (cm) & $-0.0315(-0.0442,-0.0188)$ & $<0.001$ & $0.1380(-0.2502,0.5261)$ & 0.355 \\
\hline HDL-Cholesterol (mmol/L) & $0.0019(0.0009,0.0029)$ & $<0.001$ & $-0.0253(-0.0476,-0.0030)$ & 0.004 \\
\hline Total Cholesterol (mmol/L) & $0.0006(-0.0024,0.0036)$ & 0.606 & $-0.0480(-0.1335,0.0376)$ & 0.146 \\
\hline Glycated Haemoglobin (\%) & $-0.0021(-0.0037,-0.0004)$ & 0.002 & $-0.0079(-0.0564,0.0407)$ & 0.673 \\
\hline
\end{tabular}

All analyses accounted for primary sampling units, clustering and survey weights. Adjusted linear regression models were fitted for each cardiometabolic health marker. The models controlled for: age; body mass index (except in the model with body mass index as the dependent variable); cardiovascular disease index; ethnicity; fruit and vegetable consumption; sex; smoking status; socioeconomic status; moderate-to-vigorous physical activity time; sedentary behaviour-tolight-intensity physical activity ratio; and accelerometer wear-time. Models with HDL-cholesterol and total cholesterol as the dependent variable were also controlled for both blood pressure medication and cholesterol medication. Similarly, the model with glycated haemoglobin as the dependent variable was controlled for any prescribed medication. Bold indicates statistical significance at $a=0.01$

${ }^{a}$ Beta coefficients represent a one minute increase in moderate-to-vigorous physical activity time per day

${ }^{\mathrm{b}}$ Beta coefficients represent a one unit increase in the sedentary behaviour-to-light-intensity physical activity ratio 
higher levels of HDL-cholesterol $(+0.11 \mathrm{mmol} / \mathrm{L})$, suggesting that physical inactivity in a combination with low sedentary time may have some positive relationships with health. However, the potential benefits appeared to be less numerous and consistent than those observed for physically active categories ('Busy Bees' and 'Sedentary Exercisers'). One reason for this could be in the assessed markers of cardiometabolic health. Although our study included a measure of glycaemia (HbA1c), more sensitive measures of insulin resistance, which have shown stronger associations with sedentary time $[6,19,20,46]$, were not available.

Although sedentary behaviour and MVPA have been hypothesised to be distinctive health behaviours, it is unclear to what extent the underlying mechanisms act through the same or independent pathways. This reflects a limitation in the evidence more generally where mechanisms underpinning the benefits of sedentary behaviour have not been adequately elucidated. To date, the only evidence-based independent mechanism for sedentary behaviour has been through the activation of lipoprotein lipase which has been shown to change by a factor of 10 in animal models following hind limb suspension [47]. This supports the observation in our study where low sedentary time was associated with higher HDL-cholesterol levels, even in those who were physically inactive ('Light Movers'). In contrast to sedentary behaviour, acute and chronic physiological adaptions have been well established linking higher levels of physical activity to cardiometabolic health [48-50].

\section{Strengths and limitations}

Our study has several strengths and some limitations. Strengths include; exploitation of a well-characterised national survey which employs a multifaceted stratified random sampling procedure; utilising objectively measured physical activity and sedentary behaviour data; and a wide range of sensitivity analyses to test the robustness of our findings. The method used for deriving sedentary status has both strengths and limitations in itself. In contrast to Loprinzi and colleagues [36], who used a pre-defined method for classifying high/low sedentary time, we took a conservative, data-driven approach. Differences between accelerometer characteristics, such as wear-time, across populations can have a significant effect on the average sedentary time, artificially inflating or deflating the number of participants falling within a fixed threshold. For example, based on the method used by Loprinzi and colleagues [36], less than $8 \%$ of the participants in our sample would be classified as 'Low Sedentary', and only $1.6 \%$ of the population would be categorised as physically inactive with low sedentary time i.e. 'Light Movers' (data not shown). Therefore, the approach used in our study ensures that the categories are determined in relation to the population characteristics and not influenced by measurement artefact. However, the corresponding limitation is that specific targets for intervention are difficult to define. Additional pertinent limitations that are applicable to our study include the cross-sectional design which prohibits the possibility of establishing causality (reverse-causality remains open) or that unmeasured variables were confounding observed associations. Other factors which may limit the generalizability of the findings include: the relatively small sample size for a national survey; the ethnically heterogeneous white population; non-fasting measures of HDLcholesterol and total cholesterol; and moderately high proportions of missing data in the blood analytes, particularly for HbA1c. Furthermore, a larger sample would have allowed for more dose-response categories. Lastly, our accelerometer data are based on classifying horizontal movement intensity and cannot distinguish between different postures (i.e. sitting and standing).

\section{Conclusions}

In conclusion, we demonstrate that in comparison to adults who are physically inactive with high sedentary time, those who are physically active have a more desirable health profile across multiple cardiometabolic markers even when combined with high sedentary time. In contrast, low sedentary time in the absence of physical activity is associated with higher HDL-cholesterol levels. By suggesting that being physically active may offset some of the deleterious consequences of a routinely sedentary lifestyle, this study further emphasises the importance of physical activity in the promotion and maintenance of health. However, given the observational design, the interaction and relative magnitude of effect of physical activity and sedentary behaviour on health needs further elucidation through experimental research in order to better inform public health policy and guidance.

\section{Availability of data and materials}

Permission to use the 2008 Health Survey for England accelerometer data files can be obtained from the $\mathrm{Na}$ tional Centre for Social Research (Natcen) (http:// www.natcen.ac.uk/). All other data are openly available to download from the UK Data Archive (http://discover.ukdataservice.ac.uk/series/?sn=2000021).

\section{Additional file}

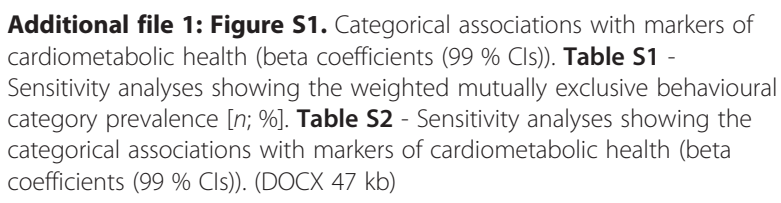

Additional file 1: Figure S1. Categorical associations with markers of cardiometabolic health (beta coefficients (99\% Cls)). Table S1 Sensitivity analyses showing the weighted mutually exclusive behavioural category prevalence $[n ; \%]$. Table S2 - Sensitivity analyses showing the categorical associations with markers of cardiometabolic health (beta coefficients (99\% Cls)). (DOCX 47 kb)

Competing interests

The authors declare that they have no competing interests. 


\section{Authors' contributions}

$\mathrm{KB}, \mathrm{CLE}$ and TY had the original idea for the analysis, which was further developed and refined by all authors. CLE processed the HSE data. KB carried out the statistical analysis and wrote the first draft of the manuscript. $K B, C L E$, DHB, DWE, JMRG, AK, LV, AJS, NS, SJHB, KK, MD and TY edited/reviewed the manuscript and approved the final version of the manuscript.

\section{Acknowledgements}

The Health Survey for England (HSE) is part of a programme of surveys commissioned by the UK National Health Service Information Centre for health and social care, carried out since 1994 by the Joint Health Surveys Unit of the National Centre for Social Research (NatCen) and the Department of Epidemiology and Public Health at the University College London Medical School. Dale W. Esliger received permission from NatCen (http://www. natcen.ac.uk/) to use the 2008 HSE accelerometer data files. The research was supported by: the UK Research Councils' Lifelong Health and Wellbeing Initiative in partnership with the Department of Health [grant number MR/ K025090/1]; the National Institute for Health Research (NIHR) Diet, Lifestyle \& Physical Activity Biomedical Research Unit based at University Hospitals of Leicester and Loughborough University; the National Institute for Health Research Collaboration for Leadership in Applied Health Research and Care - East Midlands (NIHR CLAHRC - EM); and the Leicester Clinical Trials Unit. The views expressed are those of the authors and not necessarily those of the NHS, the NIHR or the Department of Health.

\section{Author details}

'Department of Health Sciences, University of Leicester, Leicester Diabetes Centre, Leicester General Hospital, Gwendolen Road, Leicester LE5 4PW, United Kingdom. ${ }^{2}$ Diabetes Research Centre, University of Leicester, Leicester Diabetes Centre, Leicester General Hospital, Gwendolen Road, Leicester LE5 4PW, UK. ${ }^{3}$ National Institute for Health Research (NIHR) Leicester-Loughborough Diet, Lifestyle and Physical Activity Biomedical Research Unit (BRU), Leicester Diabetes Centre, Leicester General Hospital, Gwendolen Road, Leicester LE5 4PW, UK. ${ }^{4}$ School of Sport, Exercise and Health Sciences, Loughborough University, Loughborough LE11 3TU, UK. ${ }^{5}$ British Heart Foundation Glasgow Cardiovascular Research Centre (BHF GCRC), Institute of Cardiovascular and Medical Sciences, College of Medical, Veterinary and Life Sciences, University of Glasgow, Glasgow G12 8TA, UK. ${ }^{6}$ Psychiatry for the Elderly, Department of Health Sciences, University of Leicester, Leicester LE1 7RH, UK. ${ }^{7}$ Diabetes Frail Ltd, University of Aston, Birmingham B4 7ET, UK. ${ }^{8}$ Institute of Sport, Exercise \& Active Living, Victoria University, Melbourne, Australia. ${ }^{9}$ National Institute for Health Research (NIHR) Collaboration for Leadership in Applied Health Research and Care - East Midlands (CLAHRC - EM) Leicester Diabetes Centre, Leicester General Hospital, Gwendolen Road, Leicester LE5 4PW, UK.

\section{Received: 20 October 2015 Accepted: 6 January 2016} Published online: 12 January 2016

\section{References}

1. Sedentary Behaviour Research N. Letter to the Editor: Standardized use of the terms "sedentary" and "sedentary behaviours". Appl Physiol Nutr Metab. 2012;37(3):540-2.

2. Biswas A, Oh PI, Faulkner GE, Bajaj RR, Silver MA, Mitchell MS, et al. Sedentary time and its association with risk for disease incidence, mortality, and hospitalization in adults: a systematic review and meta-analysis. Ann Intern Med. 2015;162(2):123-32.

3. Chau JY, Grunseit AC, Chey T, Stamatakis E, Brown WJ, Matthews CE, et al. Daily sitting time and All-cause mortality: a meta-analysis. PLoS One. 2013;8(11):e80000.

4. Grøntved A, Hu FB. Television viewing and risk of type 2 diabetes, cardiovascular disease, and all-cause mortality: a meta-analysis. JAMA. 2011;305(23):2448-55.

5. Thorp AA, Owen N, Neuhaus M, Dunstan DW. Sedentary behaviors and subsequent health outcomes in adults: a systematic review of longitudinal studies, 1996-2011. Am J Prev Med. 2011:41(2):207-15.

6. Wilmot EG, Edwardson CL, Achana FA, Davies MJ, Gorely T, Gray LJ, et al. Sedentary time in adults and the association with diabetes, cardiovascular disease and death: systematic review and meta-analysis. Diabetologia. 2012;55(11):2895-905.

7. Edwardson CL, Gorely T, Davies MJ, Gray LJ, Khunti K, Wilmot EG, et al. Association of sedentary behaviour with metabolic syndrome: a metaanalysis. PLoS One. 2012;7(4):e34916.
8. Zhai L, Zhang Y, Zhang D. Sedentary behaviour and the risk of depression: a meta-analysis. Br J Sports Med. 2015:49(11):705-9.

9. Colley RC, Garriguet D, Janssen I, Craig CL, Clarke J, Tremblay MS. Physical activity of Canadian adults: accelerometer results from the 2007 to 2009 Canadian Health Measures Survey. Health Rep. 2011;22(1):7-14.

10. Hagströmer M, Troiano RP, Sjöström M, Berrigan D. Levels and patterns of objectively assessed physical activity - a comparison between Sweden and the United States. Am J Epidemiol. 2010;171(10):1055-64.

11. Joint Health Surveys Unit. Health Survey for England 2008: Volume 1. Leeds (UK): The Health and Social Care Information Centre. 2008. http://www.hscic gov.uk/catalogue/PUB00430/heal-surv-phys-acti-fitn-eng-2008-rep-v2.pdf. Accessed: 1 September 2015.

12. Matthews CE, Chen KY, Freedson PS, Buchowski MS, Beech BM, Pate RR, et al. Amount of time spent in sedentary behaviors in the United States, 20032004. Am J Epidemiol. 2008;167(7):875-81.

13. Department of Health. Physical Activity Guidelines in the UK: Review and Recommendations. 2011. https://www.gov.uk/government/publications/ukphysical-activity-guidelines. Accessed: 1 September 2015.

14. US Department of Health and Human Services. Physical activity guidelines for Americans. 2008. http://www.health.gov/paguidelines/guidelines/. Accessed: 1 September 2015.

15. World Health Organisation. Global recommendations on physical activity for health. 2010. http://whqlibdoc.who.int/publications/2010/9789241599979_ eng.pdf. Accessed: 1 September 2015.

16. Healy GN, Wijndaele K, Dunstan DW, Shaw JE, Salmon J, Zimmet PZ, et al. Objectively measured sedentary time, physical activity, and metabolic risk: the Australian Diabetes, Obesity and Lifestyle Study (AusDiab). Diabetes Care. 2008;31(2):369-71.

17. Katzmarzyk PT, Church TS, Craig CL, Bouchard C. Sitting time and mortality from all causes, cardiovascular disease, and cancer. Med Sci Sports Exerc. 2009;41(5):998-1005.

18. Owen N, Healy GN, Matthews CE, Dunstan DW. Too much sitting: the population health science of sedentary behavior. Exerc Sport Sci Rev. 2010;38(3):105-13.

19. Healy GN, Matthews CE, Dunstan DW, Winkler EA, Owen N. Sedentary time and cardio-metabolic biomarkers in US adults: NHANES 2003-06. Eur Heart J. 2011:32(5):590-7.

20. Henson J, Yates T, Biddle SJ, Edwardson CL, Khunti K, Wilmot EG, et al. Associations of objectively measured sedentary behaviour and physical activity with markers of cardiometabolic health. Diabetologia. 2013;56(5):1012-20.

21. Howard B, Winkler E, Sethi P, Carson V, Ridgers N, Salmon J, et al. Is lightintensity physical activity beneficially associated with cardio-metabolic risk biomarkers? J Sci Med Sport. 2014;18:e41-e42.

22. Howard B, Winkler EA, Sethi P, Carson V, Ridgers ND, Salmon JO, et al. Associations of Low- and high-intensity light activity with cardiometabolic biomarkers. Med Sci Sports Exerc. 2015;47(10):2093-101.

23. Loprinzi PD, Pariser G. Physical activity intensity and biological markers among adults with diabetes: considerations by age and gender. J Diabetes Complications. 2013;27(2):134-40

24. Warburton DE, Nicol CW, Bredin SS. Health benefits of physical activity: the evidence. CMAJ. 2006;174(6):801-9.

25. O'Donovan G, Hillsdon M, Ukoumunne OC, Stamatakis E, Hamer M. Objectively measured physical activity, cardiorespiratory fitness and cardiometabolic risk factors in the health survey for England. Prev Med. 2013:57(3):201-5.

26. Stamatakis E, Davis M, Stathi A, Hamer M. Associations between multiple indicators of objectively-measured and self-reported sedentary behaviour and cardiometabolic risk in older adults. Prev Med. 2012;54(1):82-7.

27. Stamatakis $E_{1}$ Hamer $M$, Tilling $K$, Lawlor DA. Sedentary time in relation to cardio-metabolic risk factors: differential associations for self-report vs accelerometry in working age adults. Int J Epidemiol. 2012;41(5):1328-37.

28. Evenson KR, Wen F, Metzger JS, Herring AH. Physical activity and sedentary behavior patterns using accelerometry from a national sample of United States adults. Int J Behav Nutr Phys Act. 2015;12:20

29. Marschollek M. A semi-quantitative method to denote generic physical activity phenotypes from long-term accelerometer data - the ATLAS index. PLoS One. 2013;8(5):e63522.

30. Omorou AY, Coste J, Escalon H, Vuillemin A. Patterns of physical activity and sedentary behaviour in the general population in France: cluster analysis with personal and socioeconomic correlates. J Public Health (Oxf). 2015. http://www.ncbi.nlm.nih.gov/pubmed/26071536.

31. Chomistek AK, Manson JE, Stefanick ML, Lu B, Sands-Lincoln M, Going SB, et al. Relationship of sedentary behavior and physical activity to incident 
cardiovascular disease: results from the Women's Health Initiative. J Am Coll Cardiol. 2013;61(23):2346-54.

32. Matthews CE, George SM, Moore SC, Bowles HR, Blair A, Park Y, et al. Amount of time spent in sedentary behaviors and cause-specific mortality in US adults. Am J Clin Nutr. 2012;95(2):437-45.

33. Maddison R, Jiang $Y$, Foley L, Scragg R, Direito A, Olds T. The association between the activity profile and cardiovascular risk. J Sci Med Sport. 2015; doi:10.1016/j.jsams.2015.08.001.

34. Schmid D, Ricci C, Leitzmann MF. Associations of objectively assessed physical activity and sedentary time with All-cause mortality in US adults: the NHANES study. PLoS One. 2015;10(3):e0119591.

35. Peterson MD, Snih SA, Stoddard J, McClain J, Lee I. Adiposity and Insufficient MVPA Predict Cardiometabolic Abnormalities in Adults. Med Sci Sports Exerc. 2014;46(6):1133-9.

36. Loprinzi PD, Lee $H$, Cardinal BJ. Daily movement patterns and biological markers among adults in the United States. Prev Med. 2014;60:128-30.

37. Joint Health Surveys Unit. Health Survey for England 2008: Volume 2. Leeds (UK): The Health and Social Care Information Centre. 2008. http://www.hscic. gov.uk/catalogue/PUB00430/heal-surv-phys-acti-fitn-eng-2008-rep-v3.pdf. Accessed: 1 September 2015.

38. Freedson PS, Melanson E, Sirard J. Calibration of the computer science and applications, Inc. Accelerometer. Med Sci Sports Exerc. 1998;30(5):777-81.

39. Orme M, Wijndaele K, Sharp SJ, Westgate K, Ekelund U, Brage S. Combined influence of epoch length, cut-point and bout duration on accelerometryderived physical activity. Int J Behav Nutr Phys Act. 2014;11(1):34.

40. Kozakova M, Palombo C, Morizzo C, Nolan JJ, Konrad T, Balkau B. Effect of sedentary behaviour and vigorous physical activity on segment-specific carotid wall thickness and its progression in a healthy population. Eur Heart J. 2010;31(12):1511-9.

41. Cooper AJ, Brage S, Ekelund U, Wareham NJ, Griffin SJ, Simmons RK. Association between objectively assessed sedentary time and physical activity with metabolic risk factors among people with recently diagnosed type 2 diabetes. Diabetologia. 2014;57(1):73-82.

42. Cooper AR, Sebire S, Montgomery AA, Peters TJ, Sharp DJ, Jackson N, et al. Sedentary time, breaks in sedentary time and metabolic variables in people with newly diagnosed type 2 diabetes. Diabetologia. 2012;55(3):589-99.

43. Maher C, Olds T, Mire E, Katzmarzyk PT. Reconsidering the sedentary behaviour paradigm. PLoS One. 2014;9(1):e86403.

44. Shuval K, Finley CE, Barlow CE, Gabriel KP, Leonard D, Kohl 3rd HW. Sedentary behavior, cardiorespiratory fitness, physical activity, and cardiometabolic risk in men: the cooper center longitudinal study. Mayo Clin Proc. 2014;89(8):1052-62.

45. Henson J, Yates T, Edwardson CL, Khunti K, Talbot D, Gray LJ, et al. Sedentary time and markers of chronic low-grade inflammation in a high risk population. PLoS One. 2013;8(10):e78350.

46. Yates T, Henson J, Edwardson C, Dunstan D, Bodicoat DH, Khunti K, et al. Objectively measured sedentary time and associations with insulin sensitivity: Importance of reallocating sedentary time to physical activity. Prev Med. 2015;76:79-83.

47. Hamilton MT, Hamilton DG, Zderic TW. Role of low energy expenditure and sitting in obesity, metabolic syndrome, type 2 diabetes, and cardiovascular disease. Diabetes. 2007;56(11):2655-67.

48. Ahmed HM, Blaha MJ, Nasir K, Rivera JJ, Blumenthal RS. Effects of physical activity on cardiovascular disease. Am J Cardiol. 2012;109(2):288-95.

49. Hawley JA. Exercise as a therapeutic intervention for the prevention and treatment of insulin resistance. Diabetes Metab Res Rev. 2004;20(5):383-93.

50. Hawley JA, Gibala MJ. Exercise intensity and insulin sensitivity: how low can you go? Diabetologia. 2009;52(9):1709-13.

\section{Submit your next manuscript to BioMed Central and we will help you at every step:}

- We accept pre-submission inquiries

- Our selector tool helps you to find the most relevant journal

- We provide round the clock customer support

- Convenient online submission

- Thorough peer review

- Inclusion in PubMed and all major indexing services

- Maximum visibility for your research

Submit your manuscript at www.biomedcentral.com/submit 